\title{
Substituent Optimization of $(1 \rightarrow 2)$-Glucopyranan for Tough, Strong, and Highly Stretchable Film with Dynamic Interchain Interactions
}

\author{
Abu Bin Ihsan and Yasuhito Koyama* \\ Department of Pharmaceutical Engineering, Faculty of Engineering \\ Toyama Prefectural University, 5180 Kurokawa, Imizu, Toyama 939-0398, Japan \\ *E-mail: ykoyama@pu-toyama.ac.jp
}

\section{Contents}

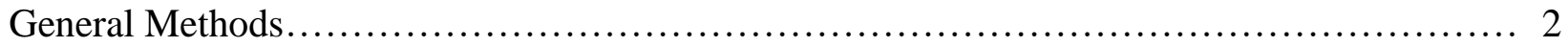

Mechanical Analysis............................................................ 2

Synthesis of Bn-GIcp(1,2) via Ring-Opening Polymerization of Cyclic Sulfite ............. 3

Typical Procedure for Hydrogenolysis of Bn-GIcp(1,2) ........................... 3

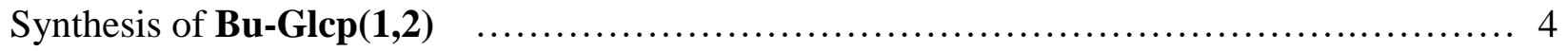

Synthesis of Hex-GIcp(1,2) .................................................. 4

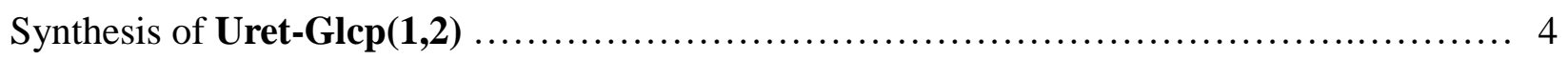

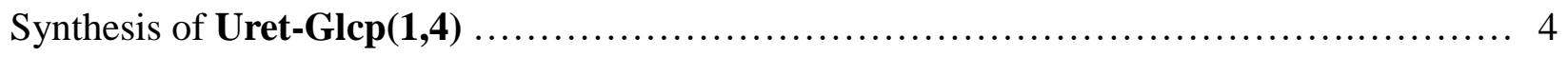

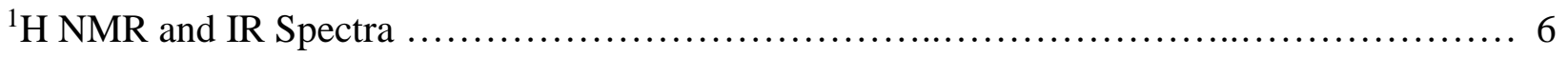

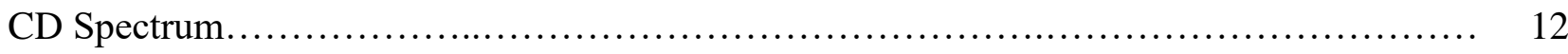

DSC Profiles................................................................ 13

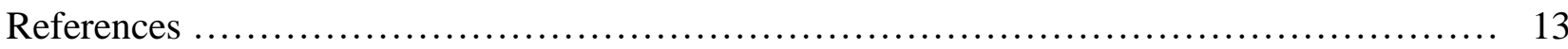




\section{General Methods.}

\section{Materials}

Dehydrated dichloromethane (Kanto Chemical Co. Inc., Tokyo, Japan), trifluoromethanesulfonic acid (TfOH, Kanto Chemical Co. Inc., Tokyo, Japan), 4-penten-1-ol (Tokyo Chemical Industry Co. Inc., Tokyo, Japan), 50 wt\% Pd(OH) (Tokyo Chemical Industry Co. Inc., Tokyo, Japan), tetrahydrofuran (THF, Kanto Chemical Co. Inc., Tokyo, Japan), dimethylsulfoxide (DMSO, Tokyo Chemical Industry Co. Inc., Tokyo, Japan), butyric acid (Tokyo Chemical Industry Co. Inc., Tokyo, Japan), hexanoic acid (Tokyo Chemical Industry Co. Inc., Tokyo, Japan), hexyl isocyanate (Tokyo Chemical Industry Co. Inc., Tokyo, Japan), N-methylpyrrolidone (NMP, Tokyo Chemical Industry Co. Inc., Tokyo, Japan), and trifluoroacetic anhydride (TFAA, Tokyo Chemical Industry Co. Inc., Tokyo, Japan) were used without further purification. Granular molecular sieves $3 \AA$ (MS 3A) as a dehydrator was activated by careful heating by a heat gun under vacuum. The other chemicals were used without purification. Benzylated $(1 \rightarrow 2)$-glucopyranans (Bn-Glcp-(1,2), 20-mer and 51-mer) were prepared by our invented technique according to the literature. ${ }^{1,2}$ Debenzylation reaction of Bn-Glcp-(1,2) was performed according to the literature. ${ }^{3}$ Amylose (synthetic, $M_{\mathrm{w}}=$ $4500 \mathrm{Da}$ ) was purchased from Glico Nutrition Co. Ltd., Osaka, Japan and used as it is without any purification.

\section{Measurements}

${ }^{1} \mathrm{H}$ NMR (400 MHz) spectra were recorded on Bruker AVANCE II 400 spectrometers (Brucker, Fällanden, Switzerland) using $\mathrm{CDCl}_{3}, \mathrm{DMSO}-d_{6}$, and $\mathrm{CD}_{3} \mathrm{OD}$ as the solvent, calibrated using an internal standard and residual undeuterated solvent signals. For the determination of functionalization ratio, we used DMSO- $d_{6}$ in the presence of small amount of $\mathrm{CF}_{3} \mathrm{COOH}$. FT-IR spectra via an attenuated total reflection (ATR) method were measured using a Perkin Elmer spectrum 100 spectrometer (Perkin Elmer, Shelton, USA). The polymer sample was in direct contact with the ATR crystal. The compression of sample was $1.5 \mathrm{kbar}$ for all experiments. A background measurement was performed in the air in the absence of any sample. The spectral range was 4000-650 $\mathrm{cm}^{-1}$. The spectra were obtained with a spectral resolution of $2 \mathrm{~cm}^{-1}$ for 100 scans. CD spectrum was taken on a JASCO J-720W spectrometer (JASCO Co. Ltd., Tokyo, Japan). Thermograms of the polymers were obtained by employing differential scanning calorimetry (DSC) to determine the glass transition temperature $\left(T_{\mathrm{g}}\right)$. The analyses were performed using a differential scanning calorimeter (DSC-60 plus) controlled by a TA-60 WS system (Shimadzu Co. Ltd., Kyoto, Japan) and equipped with a cryogenic quench cooling accessory. Samples in the order of $10 \mathrm{mg}$, weighed $( \pm 0.01 \mathrm{mg})$ using a precision scale (Advanced performance UniBloc balance, Shimadzu), were placed in hermetically sealed aluminum pans and heated at $10{ }^{\circ} \mathrm{C} / \mathrm{min}$, between $-100{ }^{\circ} \mathrm{C}$ and $100{ }^{\circ} \mathrm{C}$, under a $\mathrm{N}_{2}$ atmosphere (flow rate: $50 \mathrm{~mL} / \mathrm{min}$ ). An empty pan was used as a reference. The $T_{\mathrm{g}}$ value was calculated as the inflection point of baseline, caused by the discontinuity of specific heat of the sample.

\section{Mechanical Analysis.}

The polymer films were prepared by casting. The tensile measurements of the film were performed by a tensile tester AGS-X (Shimadzu Co. Ltd.). A $100 \mathrm{~N}$ load cell was used was for testing. The length, width, and thickness of the film were measured by using digimatic caliper (CD-15APX, $0.01 \mathrm{~mm}$, Mitutoyo Corporation). The thickness of the films was determined by using the digital micrometer at 10 points of each film. The dimension of a 
rectangular specimen was $2 \mathrm{~mm}$ in width and $1 \mathrm{~mm}$ in thickness and the distance between clamps was $12 \mathrm{~mm}$, respectively. The deformation velocity was maintained as $10 \mathrm{~mm} \mathrm{~min}^{-1}$ for the tensile tests. The elastic modulus, $E$, was calculated from the slope of the stress-strain curves at small strain (within 10\%).

\section{Synthesis of Bn-Glcp-(1,2) via Ring-Opening Polymerization of Cyclic Sulfite. ${ }^{1,2}$}

Synthesis of 20-mer of Bn-Glcp-(1,2): To a solution of cyclic sulfite (1.21 g, $2.44 \mathrm{mmol})$ and 4-pentene-1-ol (12.4 $\mu \mathrm{L}, 0.122 \mathrm{mmol}, 5.0 \mathrm{~mol} \%$ ) in $\mathrm{CH}_{2} \mathrm{Cl}_{2}(3.4 \mathrm{~mL}$ ) was added a freshly activated $\mathrm{MS} 3 \mathrm{~A}$ (ca. $50 \mathrm{mg}$ ) as a dehydrator at room temperature. After stirring for $1 \mathrm{~h}$ at room temperature, trifluoromethanesulfonic acid ( $\mathrm{TfOH}, 10.8 \mu \mathrm{L}, 0.122$ mmol) was added to the mixture. The mixture was stirred for $4 \mathrm{~d}$ at the same temperature. The reaction was quenched by the addition of $\mathrm{Et}_{3} \mathrm{~N}$ (ca. $100 \mu \mathrm{L}$ ) and the following addition of sat. aq. $\mathrm{NaHCO}_{3}$. The products were extracted with $\mathrm{CHCl}_{3}$, repeatedly. The combined organic layer was dried over $\mathrm{MgSO}_{4}$, filtered, and concentrated in vacuo to give the polymer (1.20 g, quant.) as a colorless oil. The degree of polymerization (DP) was estimated by integral ratio between the internal olefinic proton at around $5.8 \mathrm{ppm}$ and aromatic protons at around $7.4 \mathrm{ppm}$ to be 20.1 .

Synthesis of 51-mer of Bn-Glcp-(1,2): To a solution of cyclic sulfite (1.70 g, $3.42 \mathrm{mmol})$ and 4-pentene-1-ol (6.9 $\mu \mathrm{L}$, $0.069 \mathrm{mmol}, 2.0 \mathrm{~mol} \%$ ) in $\mathrm{CH}_{2} \mathrm{Cl}_{2}(4.8 \mathrm{~mL}$ ) was added a freshly activated MS 3A (ca. $50 \mathrm{mg}$ ) as a dehydrator at room temperature. After stirring for $1 \mathrm{~h}$ at room temperature, trifluoromethanesulfonic acid (TfOH, $6.1 \mu \mathrm{L}, 0.069$ mmol) was added to the mixture. The mixture was stirred for $7 \mathrm{~d}$ at the same temperature. The reaction was quenched by the addition of $\mathrm{Et}_{3} \mathrm{~N}(\mathrm{ca} .100 \mu \mathrm{L})$ and the following addition of sat. aq. $\mathrm{NaHCO}_{3}$. The products were extracted with $\mathrm{CHCl}_{3}$, repeatedly. The combined organic layer was dried over $\mathrm{MgSO}_{4}$, filtered, and concentrated in vacuo to give the polymer (1.66 g, quant.) as a colorless oil. The degree of polymerization (DP) was estimated by integral ratio between the internal olefinic proton at around $5.8 \mathrm{ppm}$ and aromatic protons at around $7.4 \mathrm{ppm}$ to be 51.2 .

Bn-Glcp-(1,2) (20-mer): ${ }^{1} \mathrm{H}$ NMR (400 MHz, $\left.298 \mathrm{~K}, \mathrm{CDCl}_{3}\right) \delta$ 7.36-6.84 (m) 5.68 (brd), 5.00-3.10 (m), 2.08-1.88 (m), 1.76-1.52 (m) ppm; ${ }^{13} \mathrm{C}$ NMR $\left(100 \mathrm{MHz}, 298 \mathrm{~K}, \mathrm{CDCl}_{3}\right) \delta$ 138.8-137.2 (m), 128.6-127.0 (m), 115.0-92.0 (m), 85.0-68.0 (m), 30.0-28.0 (m) ppm; IR (NaCl) v 3486, 3063, 3030, 2921, 2866, 1496, 1454, 1361, 1209, 1068, 1028, $736,698 \mathrm{~cm}^{-1}$.

\section{Typical Procedure for Hydrogenolysis of Bn-Glcp-(1,2). ${ }^{3}$}

The solution of benzylated $(1 \rightarrow 2)$-glucopyranan $(25.7$ mer, $1.1 \mathrm{~g})$ in THF $(60 \mathrm{~mL})$ was added to the suspension of $\mathrm{Pd}(\mathrm{OH})_{2}(50 \mathrm{wt} \%, 0.55 \mathrm{~g})$ in water $(30 \mathrm{~mL})$. The reaction system was degassed 3 times using vacuum pump and the atmosphere was replaced to $\mathrm{H}_{2}$. The mixture was stirred for $6 \mathrm{~d}$ under $\mathrm{H}_{2}$ atmosphere. The reaction mixture was filtered through a celite pad and the cake was repeatedly washed with $\mathrm{MeOH}$. The filtrate was concentrated in vacuo and dried under vacuum to give the completely debenzylated $(1 \rightarrow 2)$-glucopyranan $\mathbf{G l c p}(\mathbf{1}, \mathbf{2})$. The obtained polymer was used for next reaction without further purification: ${ }^{1} \mathrm{H}$ NMR (400 MHz, $\left.\mathrm{CD}_{3} \mathrm{OD}, 298 \mathrm{~K}\right) 4.6$ (brd, $\mathrm{H1}$ ), 3.9-3.6 (m, H3 and H6), 3.5-3.2 (m, H2,4,5), 1.3 (brd, initiator), 0.9 (brd, initiator) ppm; IR (ATR) 3295 (OH) $\mathrm{cm}^{-1}$. 


\section{Synthesis of Bu-Glcp(1,2).}

TFAA ( $4.0 \mathrm{~mL}, 0.0288 \mathrm{~mol})$ was added to butyric acid $(3.18 \mathrm{~mL}, 0.0346 \mathrm{~mol})$ at room temperature. The mixture was heated to $50{ }^{\circ} \mathrm{C}$ and stirred for $5 \mathrm{~min}$ at the same temperature. After cooling down to room temperature, Glcp(1,2) $(100 \mathrm{mg})$ was added to the mixture. The mixture was heated to $50{ }^{\circ} \mathrm{C}$, stirred for $1 \mathrm{~h}$ at the same temperature, and cooled to room temperature. The reaction was quenched by the addition of small amount of methanol-water mixture (1:1). The mixture was diluted with a small amount of $\mathrm{CHCl}_{3}$ and the solution was reprecipitated in $\mathrm{MeOH}$. The mixture was sonicated and filtered to collect solids, which were further washed with hexane and dried in vacuo to give Bu-Glcp(1,2) $(144 \mathrm{mg})$ as a hexane-insoluble part. The filtrate was concentrated in vacuo to give the hexane-soluble part $(128 \mathrm{mg})$ of Bu-Glcp(1,2). The conversion (\%) of alcohols was estimated by integral ratio between the sugar protons in a range from $5.8 \mathrm{ppm}$ to $3.0 \mathrm{ppm}$ and the methylene protons of side chains at around $2.3 \mathrm{ppm}$ to be >99\%; ${ }^{1} \mathrm{H}$ NMR (400 MHz, $\mathrm{CDCl}_{3}, 298 \mathrm{~K}$ ) 5.6-3.2 (m, Glcp), 2.3 (brd, Bu), 1.6 (brd, $\mathrm{Bu}), 0.9$ (brd, Bu) ppm; IR (ATR) $1739(\mathrm{C}=\mathrm{O}) \mathrm{cm}^{-1}$.

\section{Synthesis of Hex-GIcp (1,2).}

TFAA $(4.0 \mathrm{~mL}, 0.0288 \mathrm{~mol})$ was added to hexanoic acid $(4.33 \mathrm{~mL}, 0.0346 \mathrm{~mol})$ at room temperature. The mixture was heated to $50{ }^{\circ} \mathrm{C}$ and stirred for $5 \mathrm{~min}$ at the same temperature. After cooling down to room temperature, $\operatorname{Glcp}(\mathbf{1 , 2})(100 \mathrm{mg})$ was added to the mixture. The mixture was heated to $50{ }^{\circ} \mathrm{C}$, stirred for $12 \mathrm{~h}$ at the same temperature, and cooled to room temperature. The reaction was quenched by the addition of methanol-water mixture (1:1). The products were repeatedly extracted by $\mathrm{CHCl}_{3}$. The combined organic layer was dried over $\mathrm{MgSO}_{4}$, filtered, and concentrated in vacuo to give a crude material. The crude was purified using reverse phase column chromatography (eluent: $\mathrm{MeOH}$-water $(1: 1) \rightarrow \mathrm{MeOH})$ to give Hex-Glcp(1,2) in a quantitative yield. The conversion (\%) of alcohols was estimated by integral ratio between the sugar protons in a range from 5.8 ppm to 3.0 ppm and the methylene protons of side chains at around $2.3 \mathrm{ppm}$ to be $>99 \% ;{ }^{1} \mathrm{H} \mathrm{NMR}\left(400 \mathrm{MHz}, \mathrm{CDCl}_{3}, 298 \mathrm{~K}\right.$ ) 5.7-3.6 (m, Glcp), 2.3 (brd, Hex), 1.6 (brd, Hex), 1.3 (brd, Hex), 0.9 (brd, Hex) ppm; IR (ATR) 1745 (C=O) cm-

\section{Synthesis of Uret-GIcp(1,2).}

Hexyl isocyanate $(1.22 \mathrm{~mL}, 0.84 \mathrm{mmol})$ was added to the solution of $\mathbf{G l c p}(\mathbf{1 , 2})(136.8 \mathrm{mg})$ in NMP $(2.0 \mathrm{~mL})$. The mixture was heated at $100^{\circ} \mathrm{C}$, stirred for $12 \mathrm{~h}$ at the same temperature, and cooled to room temperature. The mixture was dialyzed in water to remove dihexylurea as a water-insoluble solid. The NMP-water mixture part was concentrated in vacuo to give Uret-Glcp(1,2) in a quantitative yield. The conversion (\%) of alcohols was estimated by integral ratio between the sugar protons in a range from $5.8 \mathrm{ppm}$ to $3.3 \mathrm{ppm}$ and the methylene protons of side chains at around $3.0 \mathrm{ppm}$ to be $>99 \%$; ${ }^{1} \mathrm{H}$ NMR (400 MHz, $\mathrm{CDCl}_{3}, 298 \mathrm{~K}$ ) 5.8-3.3 (m, Glcp), 3.0 (brd), 1.4 (brd), 1.2 (brd), 0.7 (brd) ppm; IR (ATR) $3336(\mathrm{~N}-\mathrm{H}), 1704(\mathrm{C}=\mathrm{O}) \mathrm{cm}^{-1}$.

\section{Synthesis of Uret-GIcp $(1,4)$.}

Hexyl isocyanate $(1.22 \mathrm{~mL}, 0.84 \mathrm{mmol})$ was added to the solution of amylose $(136.8 \mathrm{mg})$ in NMP $(2.0 \mathrm{~mL})$. The mixture was heated at $100{ }^{\circ} \mathrm{C}$, stirred for $12 \mathrm{~h}$ at the same temperature, and cooled to room temperature. The mixture was dialyzed in water to remove dihexylurea as a water-insoluble solid. The NMP-water mixture part was 
concentrated in vacuo to give Uret-Glcp(1,4) in a quantitative yield. The conversion $(\%)$ of alcohols was estimated by integral ratio between the sugar protons in a range from $5.2 \mathrm{ppm}$ to $3.2 \mathrm{ppm}$ and the methylene protons of side chains at around $3.1 \mathrm{ppm}$ to be $>99 \%$; ${ }^{1} \mathrm{H}$ NMR (400 MHz, $\mathrm{CDCl}_{3}, 298 \mathrm{~K}$ ) 5.2-3.2 (m, Glcp), 3.1 (brd), 1.4 (brd), 1.2 (brd), 0.7 (brd, Hex) ppm; IR (ATR) $3295(\mathrm{~N}-\mathrm{H}), 1667(\mathrm{C}=\mathrm{O}) \mathrm{cm}^{-1}$. 


\section{${ }^{1} \mathrm{H}$ NMR and IR Spectra.}

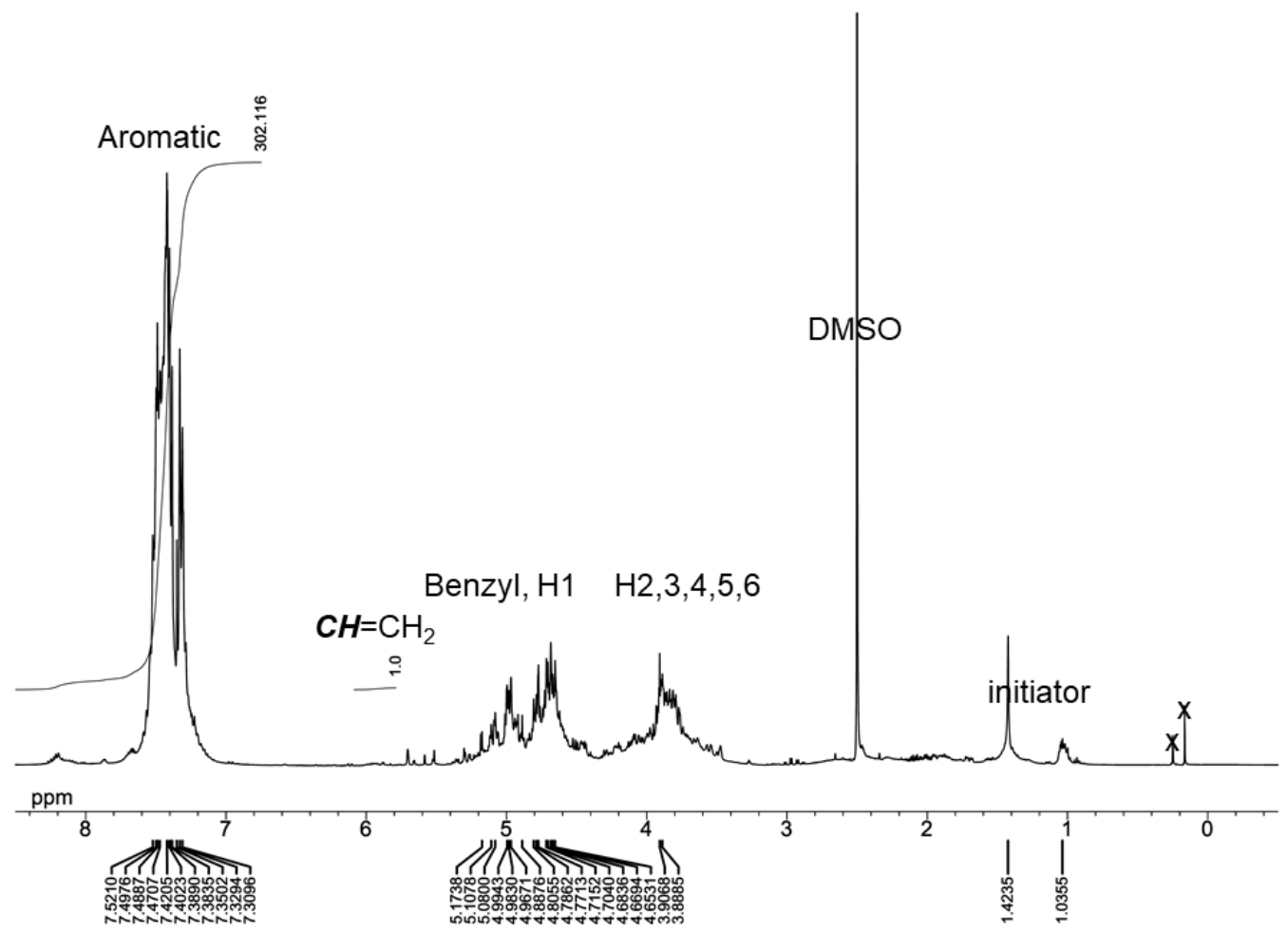

Figure S1. ${ }^{1} \mathrm{H}$ NMR spectrum of Bn-GIcp(1,2) $\left(20.1\right.$ mer, $400 \mathrm{MHz}$, DMSO- $d_{6}$ with a small amount of $\mathrm{CF}_{3} \mathrm{COOH}$, $298 \mathrm{~K})$.

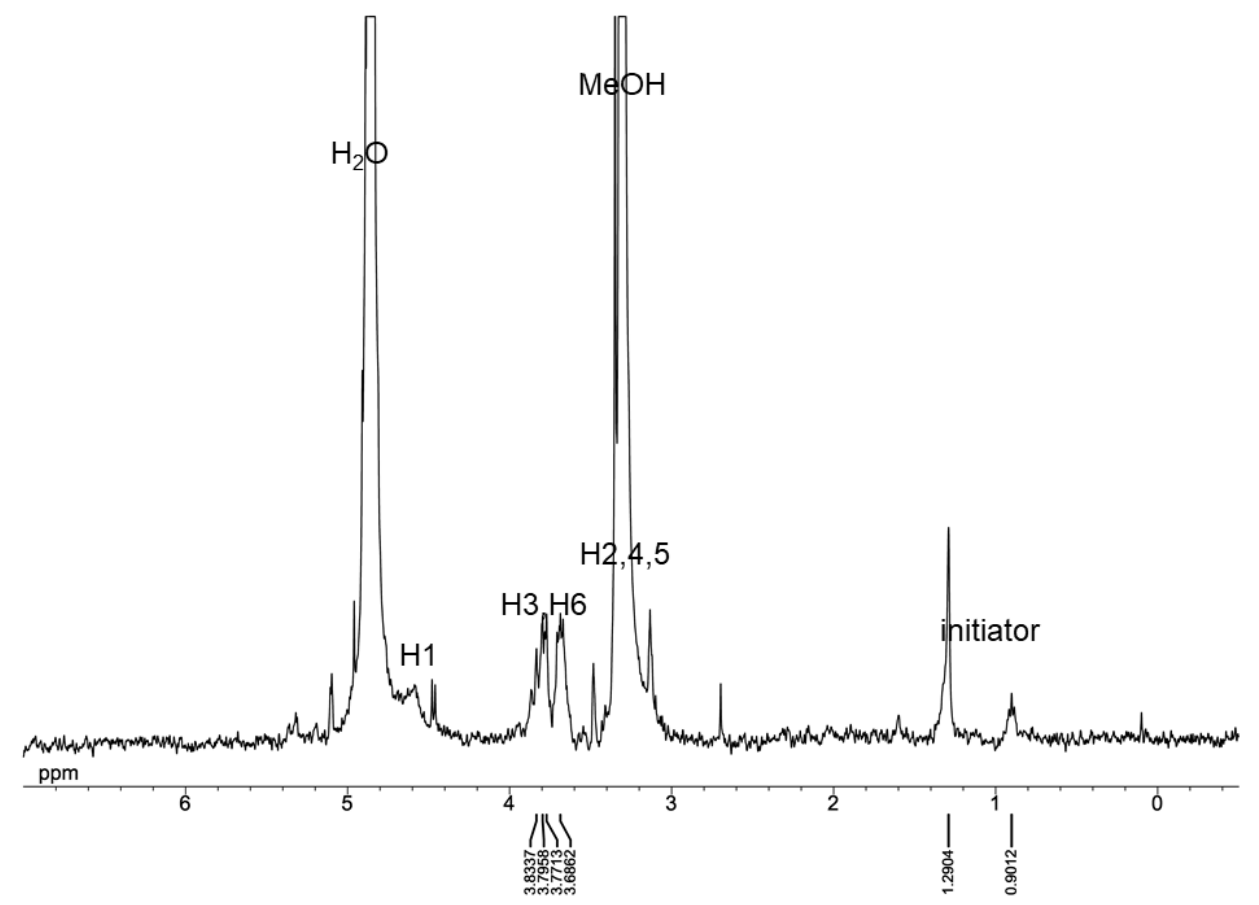

Figure S2. ${ }^{1} \mathrm{H}$ NMR spectrum of $\mathbf{G l c p}(\mathbf{1 , 2})\left(400 \mathrm{MHz}, \mathrm{CD}_{3} \mathrm{OD}, 298 \mathrm{~K}\right)$. 


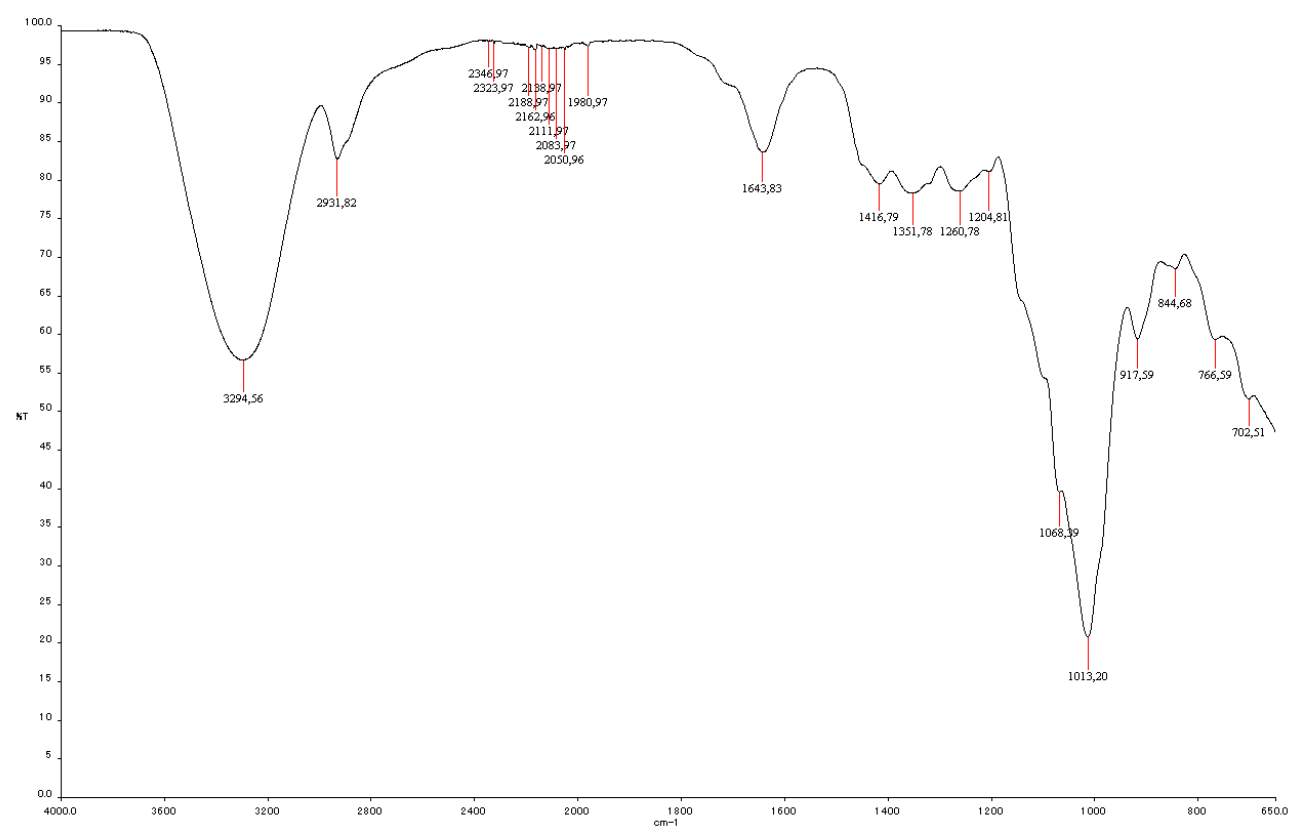

Figure S3. IR spectrum of Glcp(1,2) (ATR).

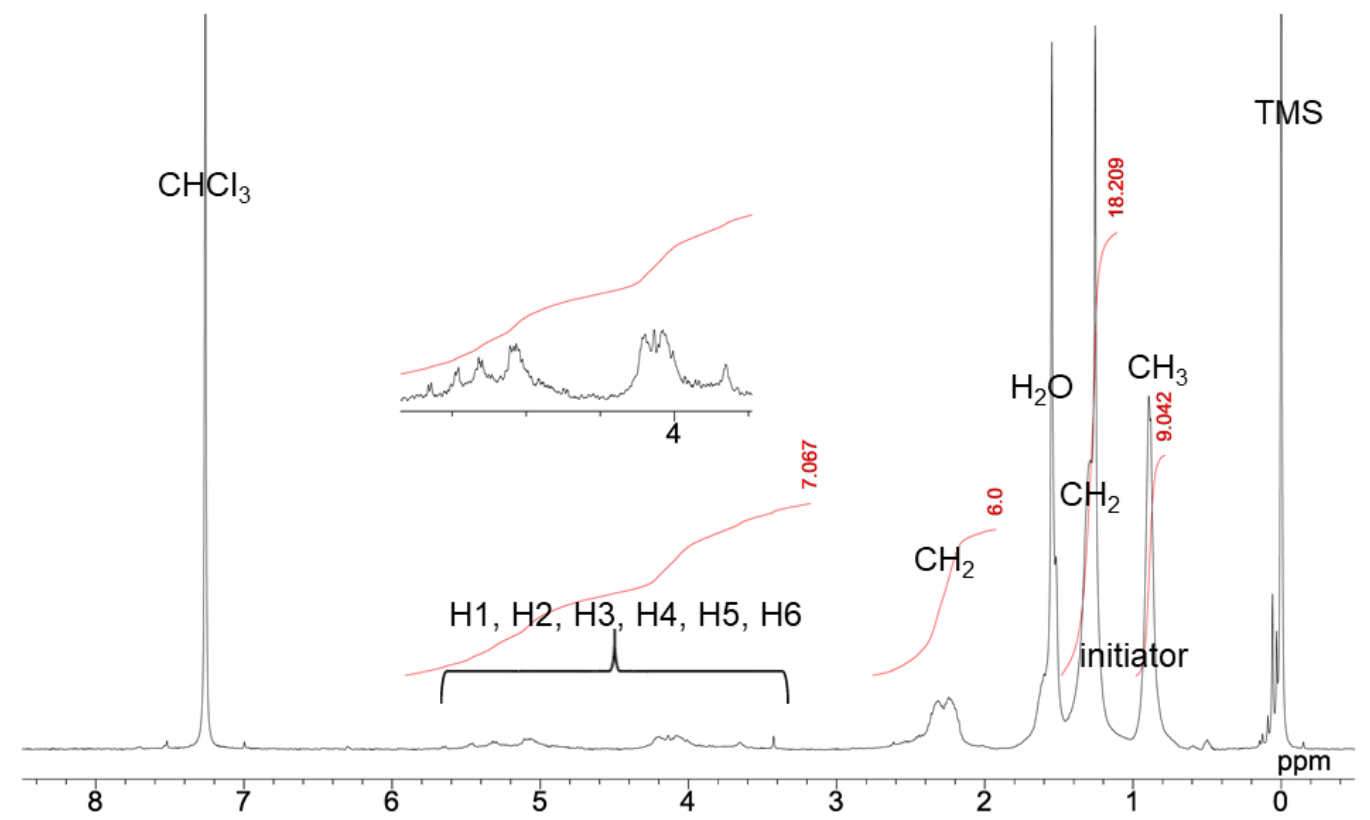

Figure S4. ${ }^{1} \mathrm{H}$ NMR spectrum of Bu-Glcp(1,2) $\left(400 \mathrm{MHz}, \mathrm{CDCl}_{3}, 298 \mathrm{~K}\right)$. 


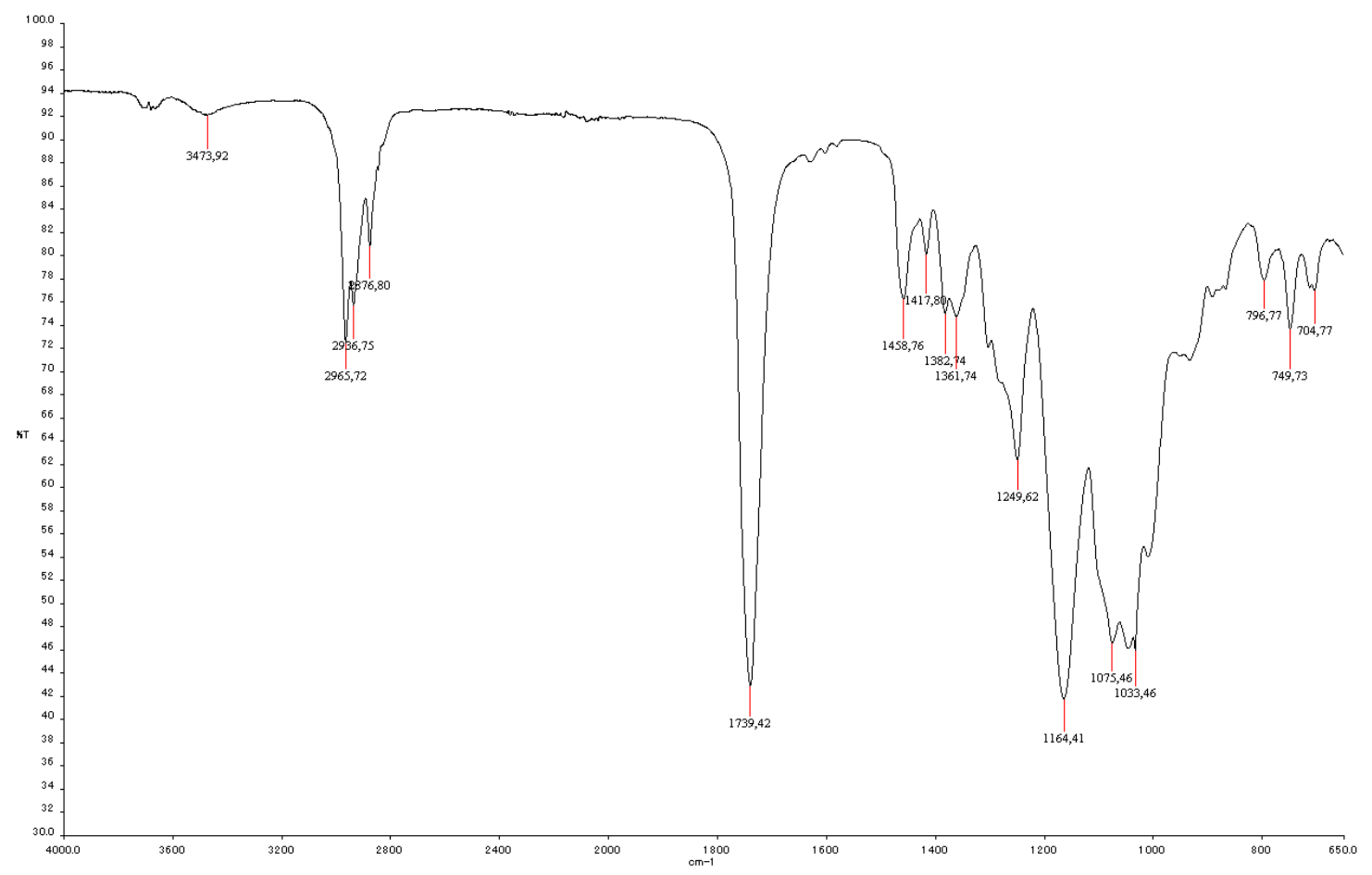

Figure S5. IR spectrum of Bu-Glcp(1,2) (ATR).

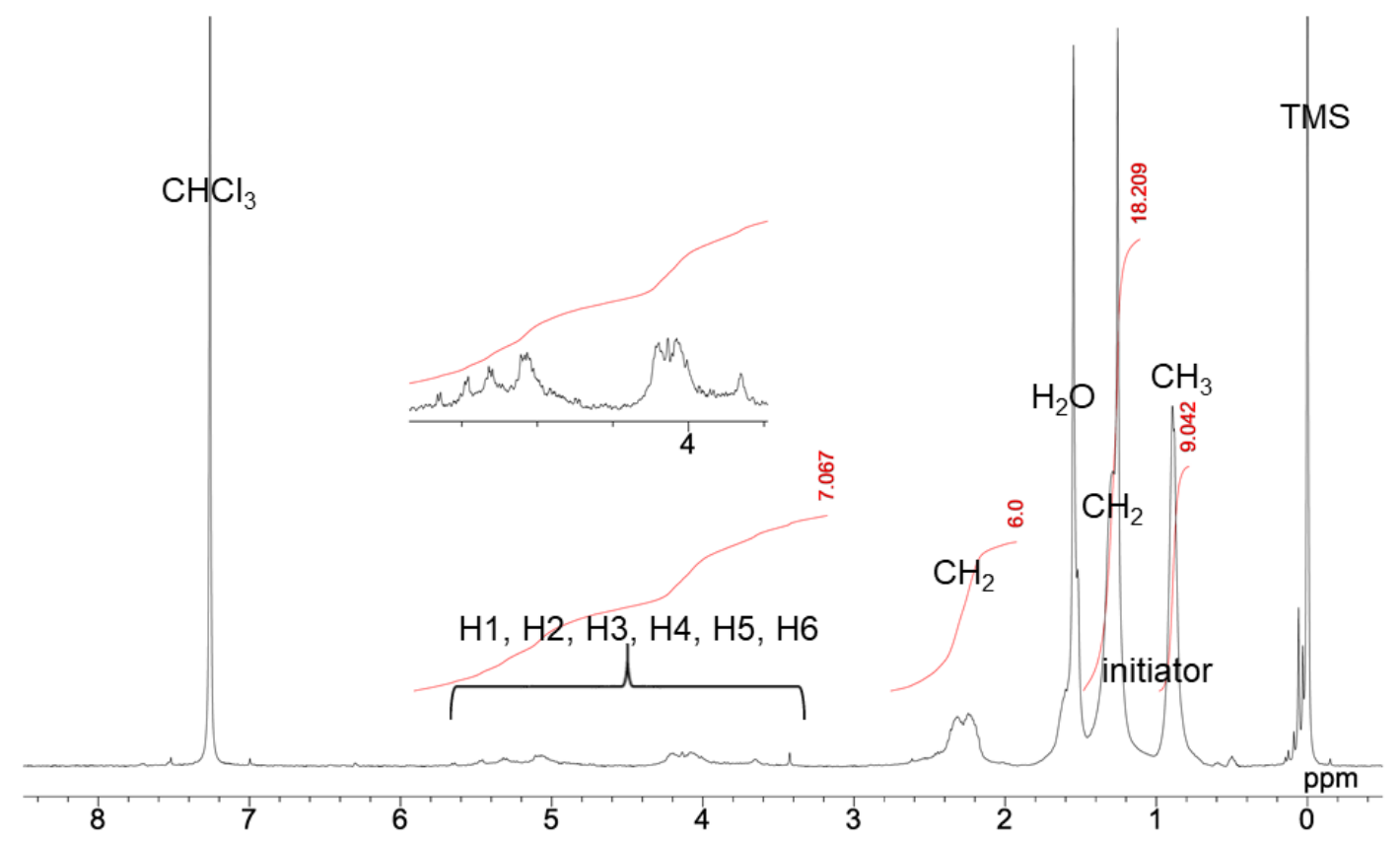

Figure S6. ${ }^{1} \mathrm{H}$ NMR spectrum of Hex-Glcp(1,2) $\left(400 \mathrm{MHz}, \mathrm{CDCl}_{3}, 298 \mathrm{~K}\right)$. 


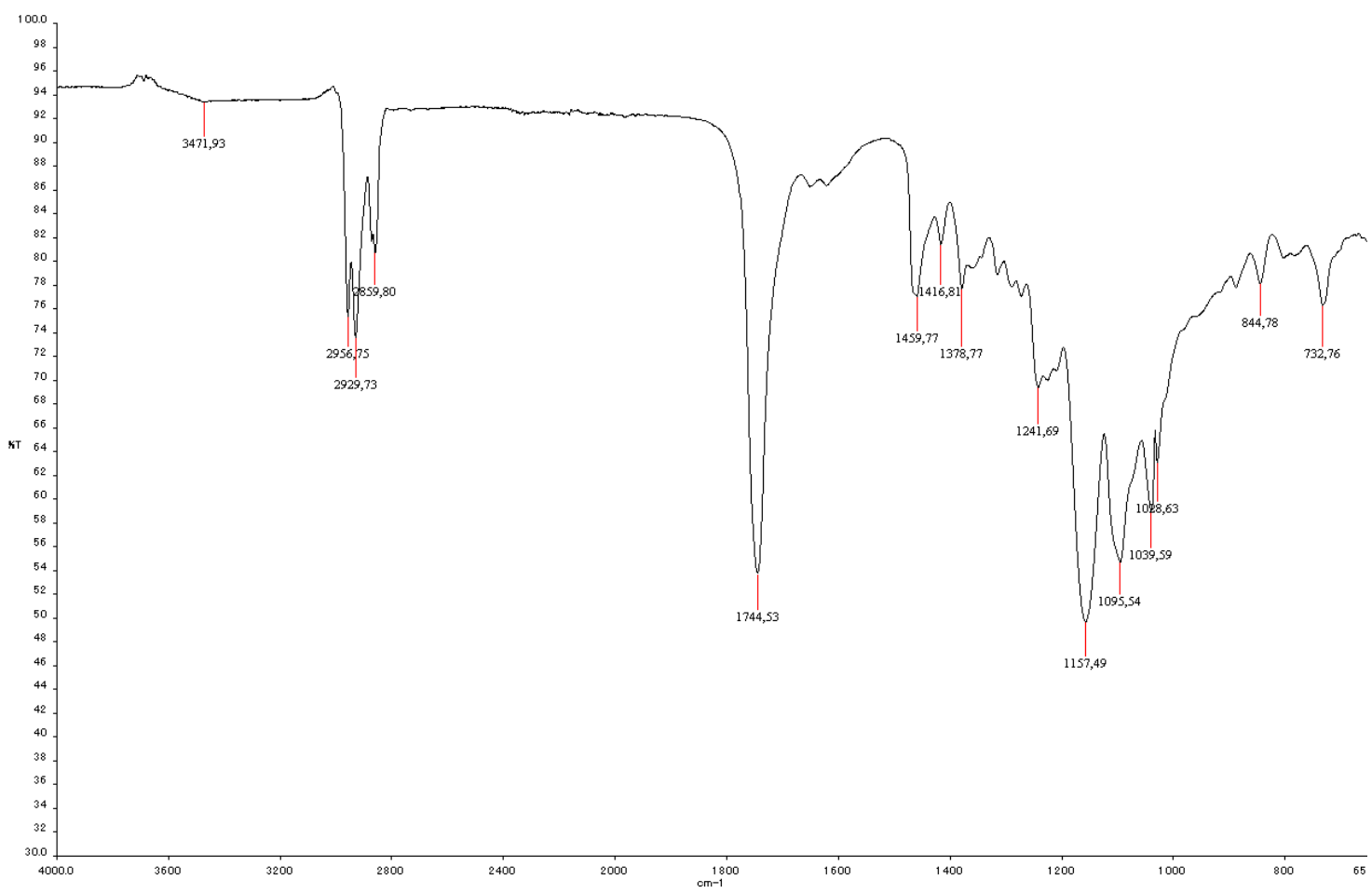

Figure S7. IR spectrum of Hex-Glcp(1,2) (ATR).

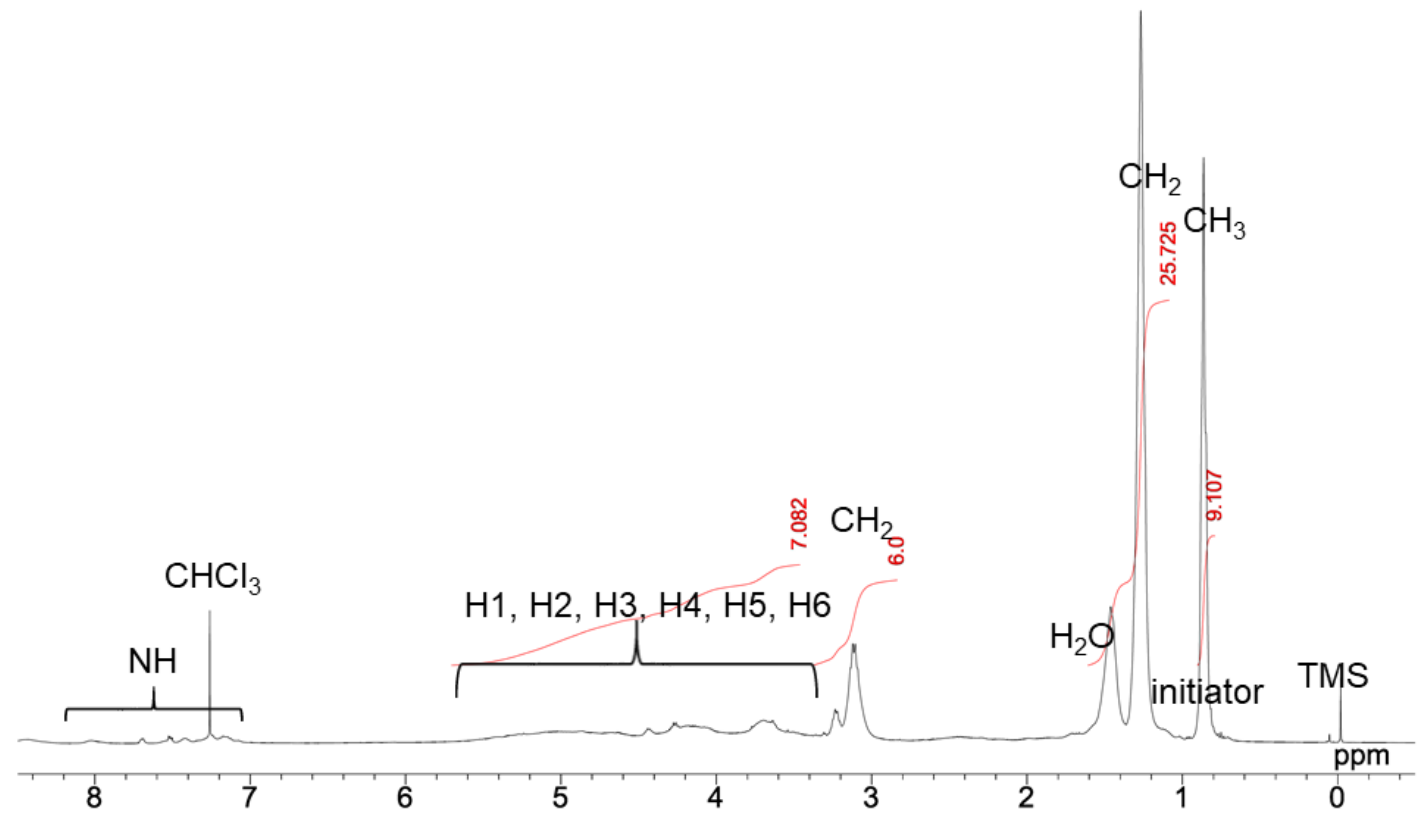

Figure S8. ${ }^{1} \mathrm{H}$ NMR spectrum of Uret-Glcp(1,2) $\left(400 \mathrm{MHz}, \mathrm{CDCl}_{3}, 298 \mathrm{~K}\right)$. 


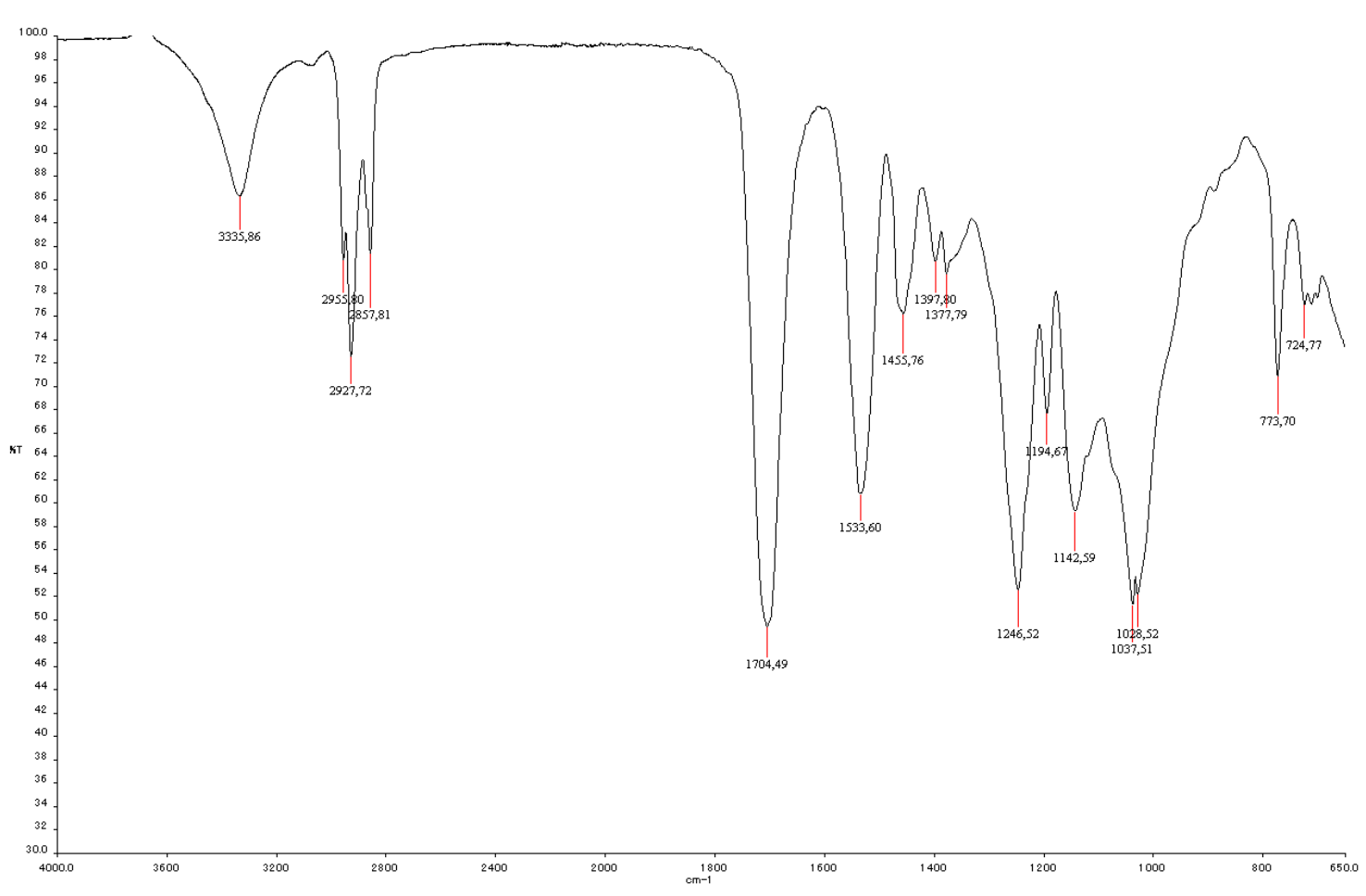

Figure S9. IR spectrum of fresh Uret-Glcp(1,2) (ATR).

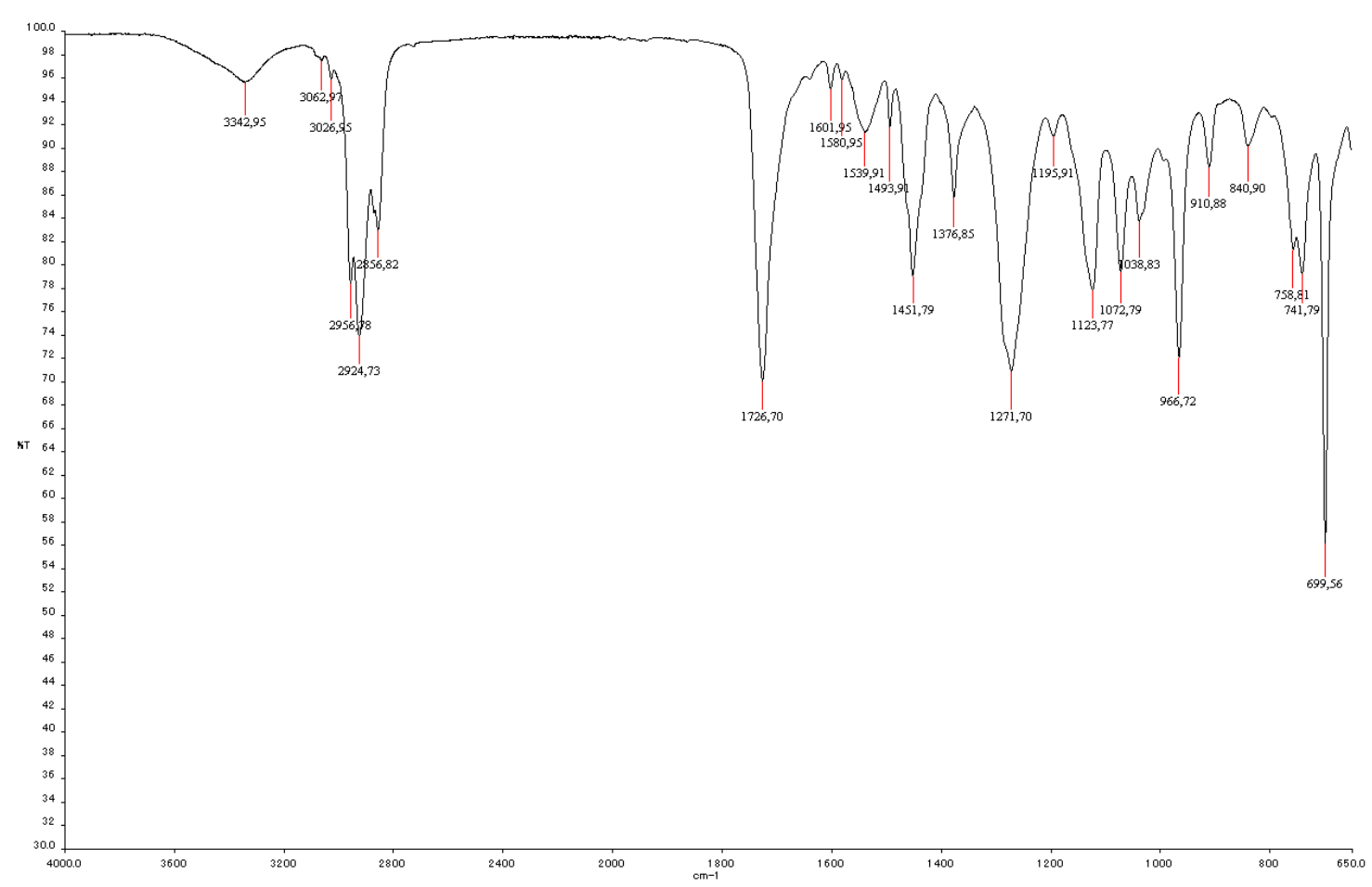

Figure S10. IR spectrum of stressed Uret-Glcp(1,2) (ATR). 


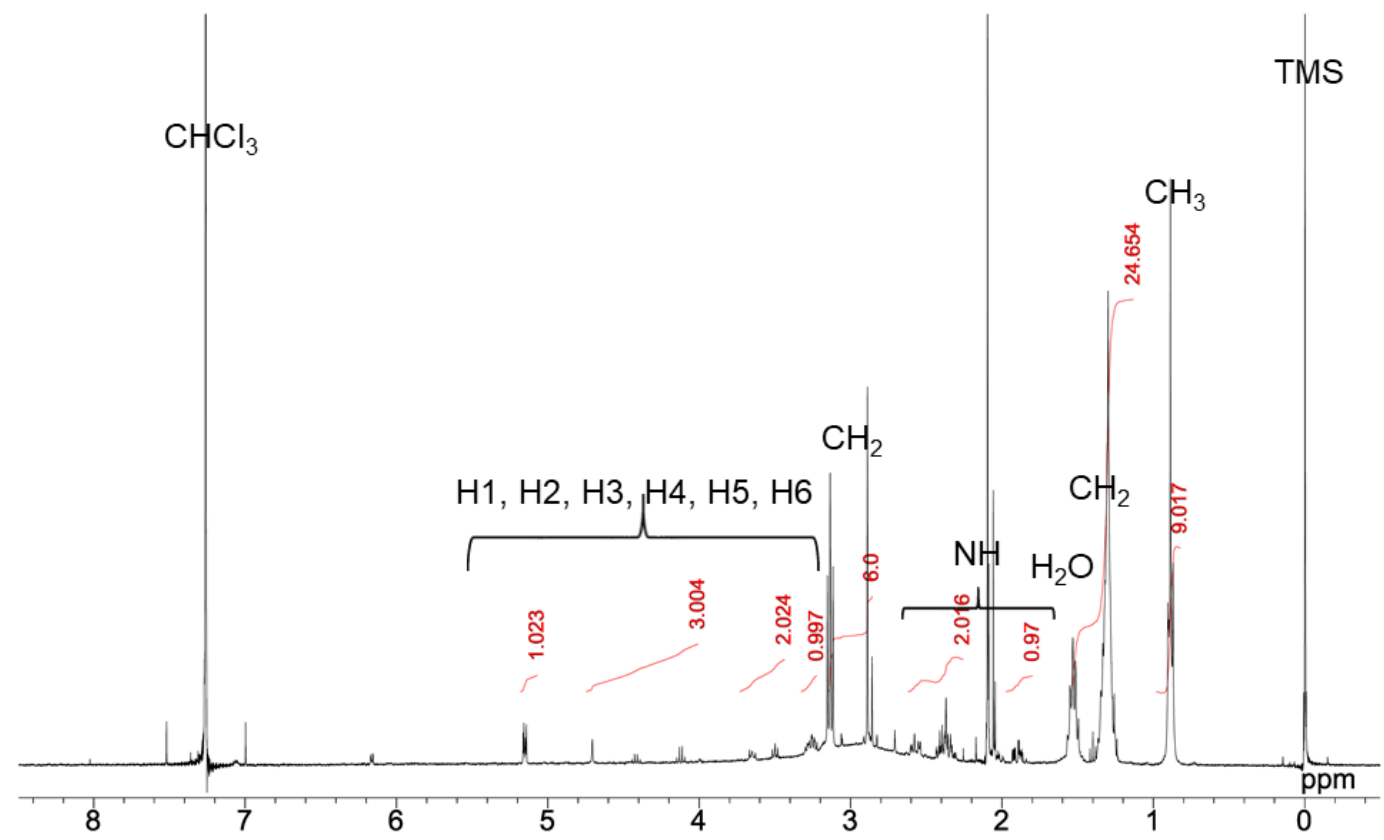

Figure S11. ${ }^{1} \mathrm{H}$ NMR spectrum of Uret-Glcp(1,4) $\left(400 \mathrm{MHz}, \mathrm{CDCl}_{3}, 298 \mathrm{~K}\right)$.

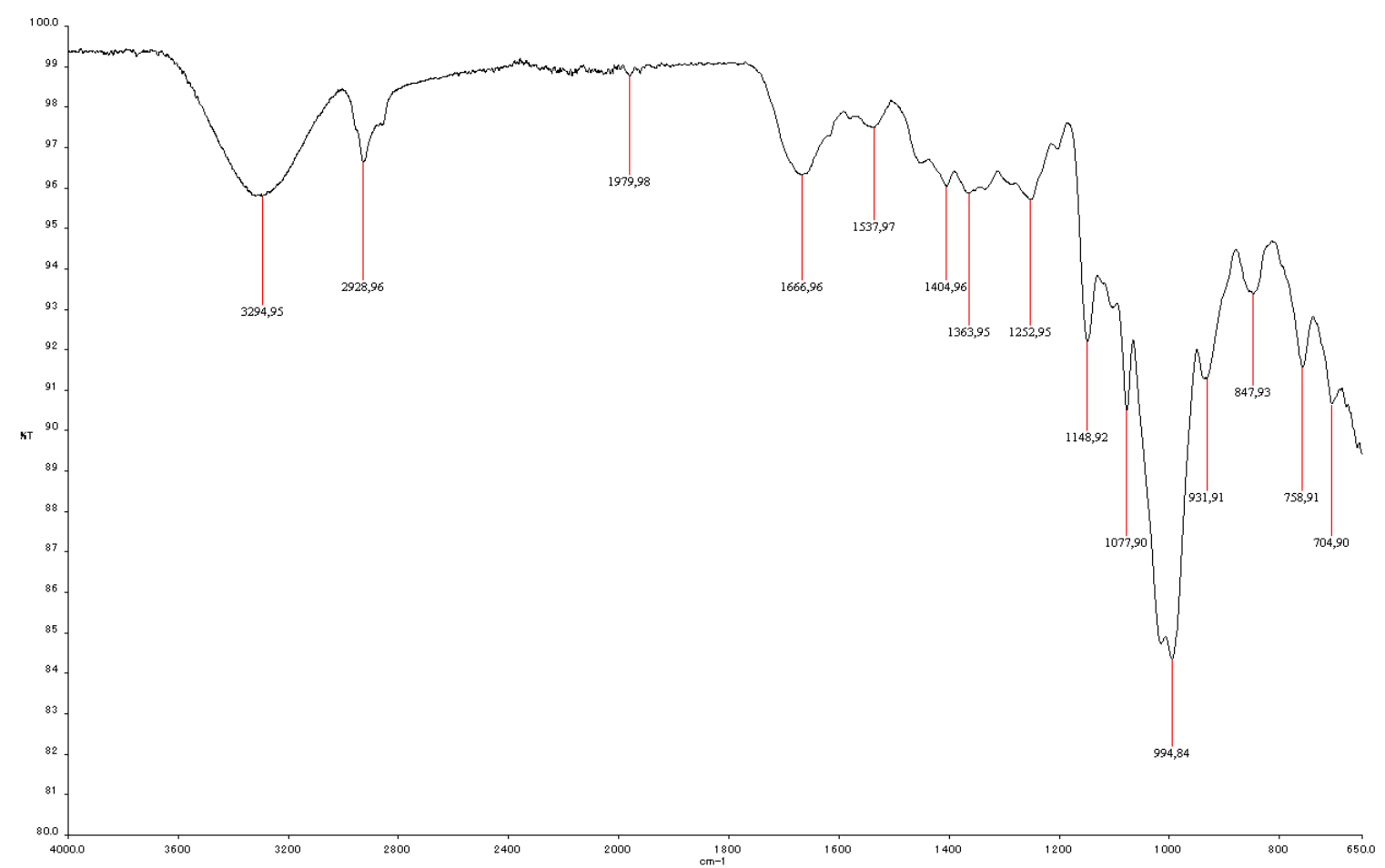

Figure S12. IR spectrum of Uret-GIcp(1,4) (ATR). 


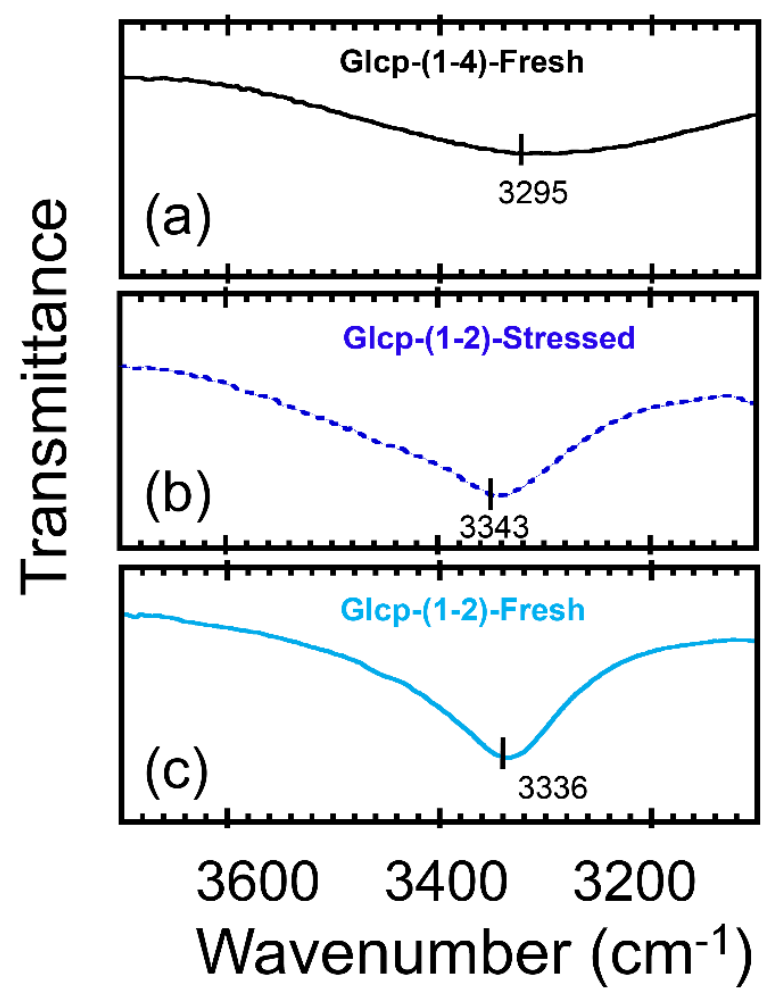

Figure S13. Partial IR spectra of (a) Uret-GIcp(1,4), (b) stressed Uret-Glcp(1,2), and (c) fresh Uret-Glcp(1,2) films (ATR).

CD spectrum.

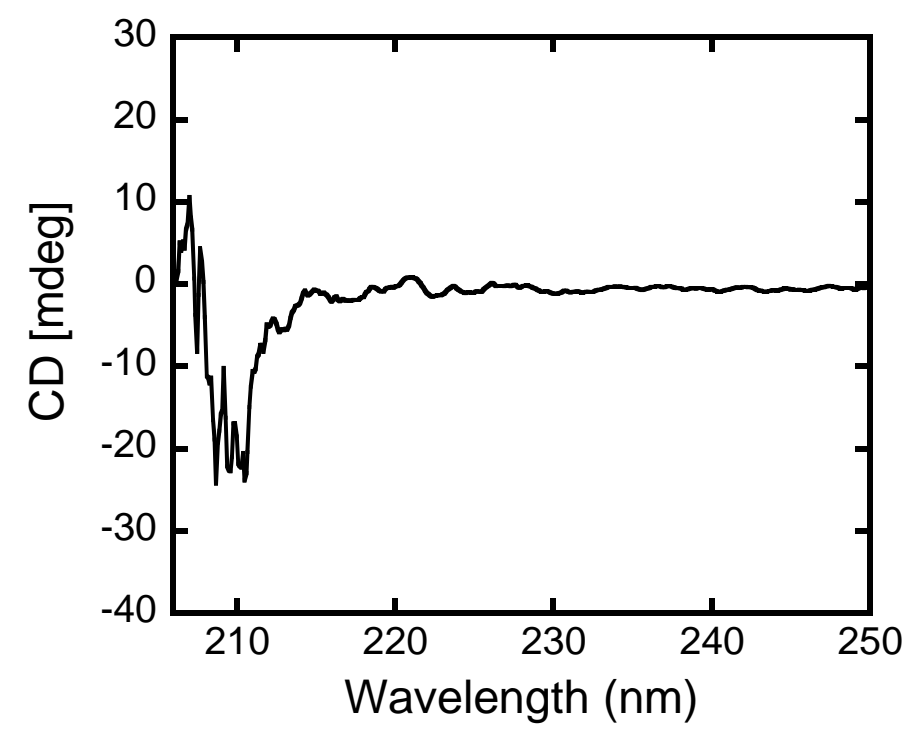

Figure S14. CD spectrum of Uret-Glcp(1,4) $\left(1.0 \mathrm{mM}, \mathrm{ClCH}_{2} \mathrm{CH}_{2} \mathrm{Cl}, 298 \mathrm{~K}\right)$. 


\section{DSC Profiles.}

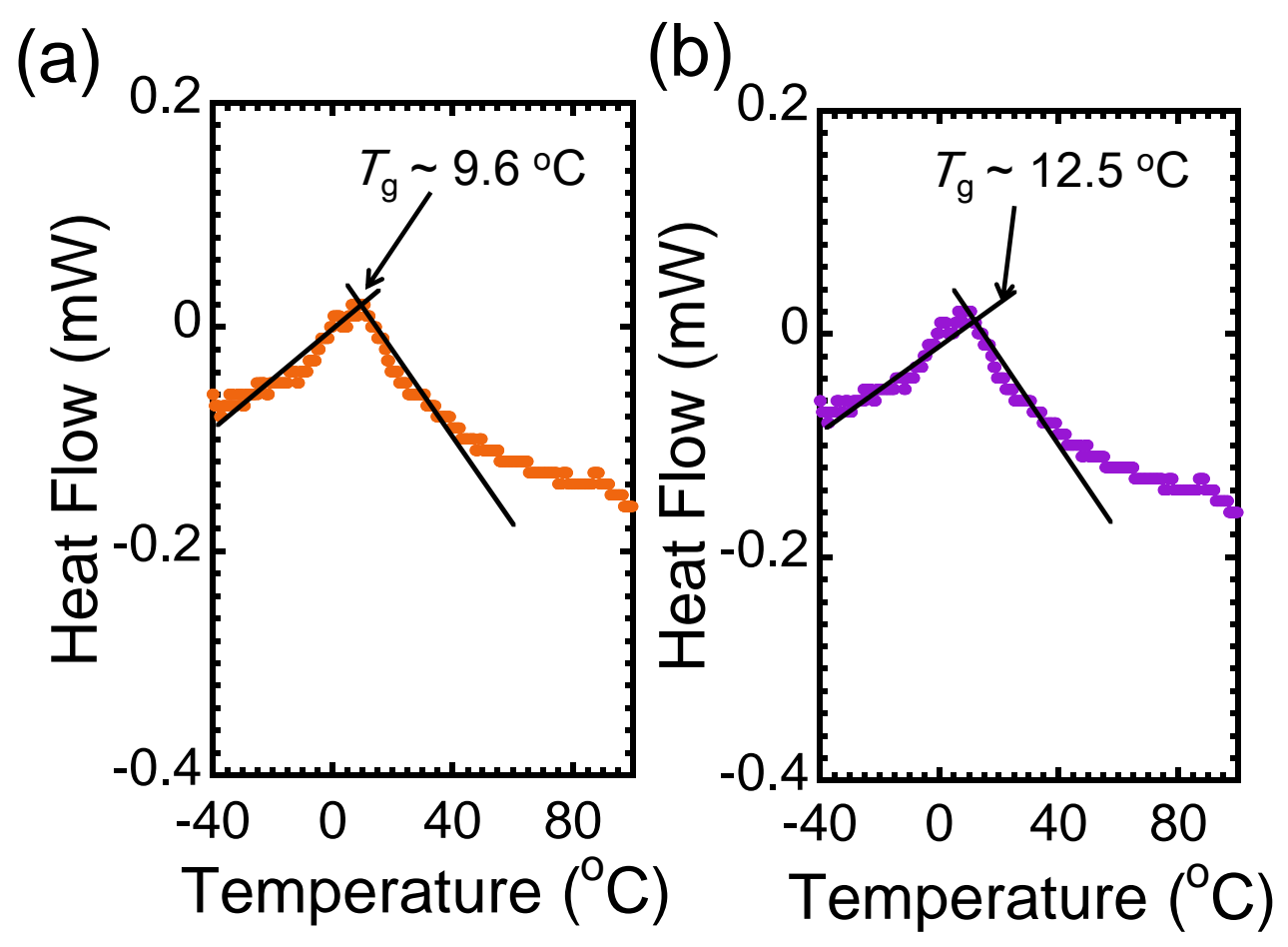

Figure S15. DSC profiles of (a) Bu-GIcp(1,2) and (b) Hex-GIcp(1,2).

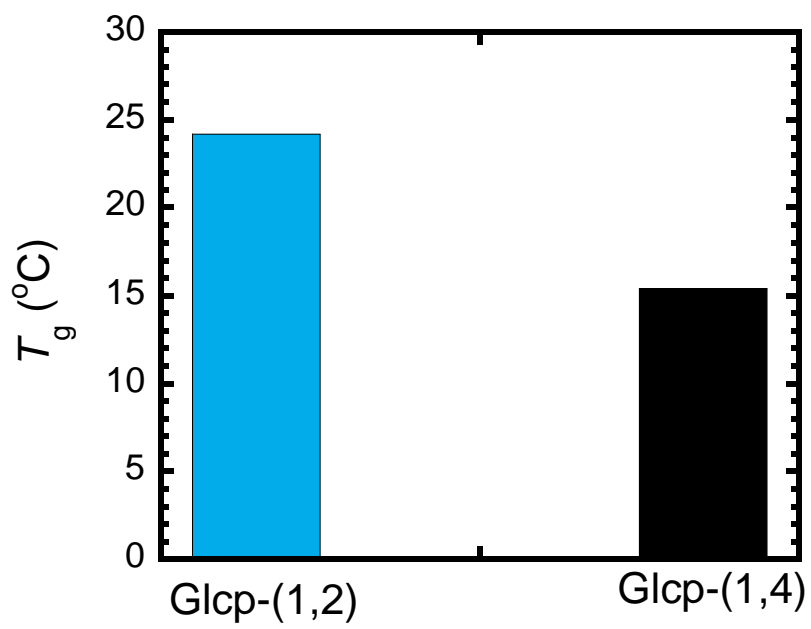

Figure S16. Effects of glycosidic linkage on the $T_{\mathrm{g}}$ of Uret-Glcp films.

\section{References.}

1) S. S. Shetty, Y. Koyama, Tetrahedron Lett., 2016, 57, 3657-3661.

2) S. S. Shetty, Y. Koyama, T. Nakano, Chem. Lett., 2016, 45, 1021-1023.

3) A. B. Ihsan, Y. Kawaguchi, H. Inokuchi, H. Endo, Y. Koyama, RSC Adv. 2019, 9, 26214-26218. 